REFERENCE

I Sehgal VN, Jain MK, Mathur RP. Pityriasis rubra pilaris in Indians. Br $\mathcal{J}$ Dermatol 1989; 121: 82 I-2.

\title{
Direct antiproliferative effect of cyclosporin $A$ on cultured keratinocytes and fibroblasts
}

SIR, We were interested to read the recently published report ${ }^{1}$ demonstrating a direct antiproliferative effect of cyclosporin A on cultured keratinocytes and fibroblasts. These authors observed a reversible, dose-dependent inhibitory effect and that the presence of serum attenuated this response. These findings were of interest to us because we previously observed the same phenomena and reported them in several earlier publications. ${ }^{2.3} \mathrm{We}$ cannot understand these citation omissions of our in vitro findings because they were properly cited by investigators confirming an in vivo direct antiproliferative effect on keratinocytes ${ }^{4}$ and this reference was included in the bibliography of their paper.

The authors raised the question of the possible molecular mechanism by which cyclosporin A inhibits keratinocyte growth, and we suggest that it may exert its antiproliferative effect by decreasing the number of high affinity epidermal growth factor receptors. ${ }^{5}$

Departments of Pathology and Dermatology,

B.J.NICKOLOFF The University of Michigan Medical School, R.S.MITRA I30I Catherine Road,

Ann Arbor,

MI 48109-0602, U.S.A.

\section{REFERENCES}

I Dykes PJ, Brunt J, Marks R. The effect of cyclosporin on human epidermal keratinocytes in vitro. Br $\mathcal{f}$ Dermatol 1990; 122: $173-80$.

2 Nickoloff BJ, Fisher GJ, Mitra RS, Voorhees JJ. Additive and synergistic antiproliferative effects of cyclosporin A and gamma interferon on cultured human keratinocytes. Am $\mathcal{Y}$ Pathol 1988; 13 I: $12-18$.

3 Nickoloff BJ, Fisher GJ, Mitra RS, Voorhees JJ. Direct cytopathic effects of cyclosporine A on rapidly proliferating cultured keratinocytes and dermal fibroblasts. Trans Proceed I988; 20 (Suppl 4): 85-90.

4 Urabe MD, Kanitakis J, Viac J, Thivolet J. Cyclosporin A inhibits directly in vivo keratinocyte proliferation of living human skin. $\mathcal{F}$ Invest Dermatol 1989; 92: 755-7.

5 Nickoloff BJ, Mitra RS. Inhibition of ${ }^{125}$ I-epidermal growth factor binding to cultured keratinocytes by antiproliferative molecules gamma interferon, cyclosporin $\mathrm{A}$ and transforming growth factor-beta. $\mathcal{f}$ Invest Dermatol 1989; 93: 799-803.

\section{Persistent bite reactions responsive to photochemotherapy}

SIR, Cutaneous reactions to bites from arthropods are common and immediate reactions are pruritic, erythematous papules that resolve within an hour. Sometimes a delayed reaction occurs and these lesions are intensely pruritic and the intensity and duration of symptoms is variable and often correlates with the number of bites received. ${ }^{1}$ We describe two cases of patients with persistent insect bite reactions who having failed standard therapy, were successfully treated with oral psoralens and long-wave ultraviolet light (PUVA).

Two middle-aged Caucasian men presented with multiple insect bites. Patient I noted multiple chiggers on his body on a hunting trip. Both men had pruritic, erythematous urticarial papules on their neck, trunk 
This document is a scanned copy of a printed document. No warranty is given about the accuracy of the copy. Users should refer to the original published version of the material. 